\title{
ANALISA PERBANDINGAN PERHITUNGAN KAPASITAS RUAS JALAN METODE PKJI 2014 DENGAN METODE GREENSHIELD, GREENBERG DAN UNDERWOOD
}

\author{
Nur Maya Sari ${ }^{1}$, Salonten $^{2}$, dan Supiyan ${ }^{3}$ \\ ${ }^{123}$ Program Studi Teknik Sipil, Fakultas Teknik, Universitas Palangka Raya \\ E-mail: nurmayasari534@gmail.com ${ }^{1}$, salonten@jts.upr.ac.id ${ }^{2}$, dan \\ supiyan@eng.upr.ac.id ${ }^{3} / \mathbf{H P . + 6 2 8 5 3 4 5 9 2 7 4 6 3}{ }^{1}$
}

\begin{abstract}
ABSTRAK
Jalan Ahmad Yani adalah salah satu jalan perkotaan yang terdapat di kota Palangka Raya yang memiliki volume lalu lintas kendaraan cukup tinggi. Untuk mengetahui bagaimana keadaan lalu lintas yang terjadi maka dilakukan analisa kapasitas jalan Ahmad Yani dengan metode PKJI 2014 dan membuat perbandingan perhitungan kapasitas jalan menggunakan metode Greenshield, Greenberg dan Underwood. Dilakukan survei selama 5 hari, dengan menggunakan metode PKJI 2014 dan membandingkan antara tiga model untuk mengetahui hubungan matematis antara parameter Volume-Kecepatan-Kepadatan dan koefisien determinasi $\left(\mathrm{R}^{2}\right)$ yang tertinggi untuk lima hari survei. Dari ketiga model didapatkan untuk Model Greenshield, Koefisien determinasi tertinggi di peroleh hari selasa pada segmen ruas jalan AIS Nasution-W. Sudirihosodo dengan $\mathrm{R}^{2}=0,471$ dengan Kapasitas $(\mathrm{Vm})=1477,135 \frac{\mathrm{skr}}{\mathrm{jam}}$, Kepadatan $(\mathrm{Dj})=81,139 \frac{\mathrm{skr}}{\mathrm{km}}$, Kecepatan maksimum $(\mathrm{Sm})=36,41 \mathrm{~km} / \mathrm{jam}$. Untuk Model Greenberg Koefisien determinasi tertinggi di peroleh pada hari kamis pada segmen jalan W. Sudirohosodo-AIS Nasution dengan $\mathrm{R}^{2}=0,392$, Kapasitas $(\mathrm{Vm})=3179,956 \mathrm{skr} / \mathrm{jam}$, Kepadatan $(\mathrm{Dj})=506,386 \mathrm{skr} / \mathrm{km}$, Kecepatan maksimum $(\mathrm{Sm})=17,07 \mathrm{~km} / \mathrm{jam}$. Untuk model Underwood Koefisien determinasi tertinggi di peroleh pada hari selasa segmen ruas jalan AIS NasutionW. Sudirihosodo dengan $\mathrm{R}^{2}=0,489$, Kapasitas $(\mathrm{Vm})=1705,128 \mathrm{skr} / \mathrm{jam}$, Kepadatan (Dm) V=58,82skr $/ \mathrm{km}$, Kecepatan maksimum $(\mathrm{Sm})=28,988 \mathrm{~km} / \mathrm{jam}$. Dari tiga model yaitu Greenshield, Greenberg, dan Underwood yang mendekati dengan nilai kapasitas menggunakan PKJI 2014 dengan kapasitas Vm=2794,1 skr/jam adalah model Underwood pada hari jumat pada segmen 2 arah H. IkapIskandar dengan kapasitas $\mathrm{Vm}=2800,382 \mathrm{skr} / \mathrm{jam}$ dengan $\mathrm{r}^{2}=0,243$ hubungan antara (S-D) $68,511 x \exp (-\mathrm{D} / 111,11)$ persamaan $(\mathrm{V}-\mathrm{S}) \mathrm{V}=111,11 \mathrm{Sx}$ Ln $(68,511 / \mathrm{S})$ persamaan (V-D) V=68,511.D exp (-D/111,11).
\end{abstract}

Kata kunci: greenberg, greenshield, underwood, kapasitas PKJI 2014.

\section{ABSTRACT}

Ahmad Yani street is one of the urban roads in the city of Palangka Raya which has a high volume of vehicle traffic. To find out how the traffic condition is happening, the Ahmad Yani road capacity analysis is conducted using the 2014 PKJI method and makes comparisons of road capacity calculations using the Greenshield, Greenberg and Underwood methods. A 5 day survey was conducted, using the 2014 PKJI method and comparing the three models to determine the mathematical relationship between the parameters Volume-Velocity-Density and the highest coefficient of determination $\left(R^{2}\right)$ for the five survey days. From the three models obtained for the Greenshield Model the highest determination coefficient is 
obtained on Tuesday on the AIS Nasution-W road segment. Sudirihosodo with $R^{2}=0.471$ with capacity $(\mathrm{Vm})=1477.135 \mathrm{cur} / \mathrm{hour}$, density $(D j)=81.139 \mathrm{skr} / \mathrm{km}$, maximum speed $(\mathrm{Sm})=36.41 \mathrm{~km} / \mathrm{hour}$. For the Greenberg Model the highest coefficient of determination is obtained on Thursday on the road segment $W$. Sudirohosodo-AIS Nasution with $R^{2}=0.392$, Capacity $(\mathrm{Vm})=3179,956 \mathrm{cur} / \mathrm{hour}$, Density $(D j)=506,386 \mathrm{cur} / \mathrm{km}$, maximum speed $(\mathrm{Sm})=17.07 \mathrm{~km} / \mathrm{hour}$. For the Underwood model, the highest coefficient of determination is obtained on Tuesday for the AIS Nasution-W road segment. Sudirihosodo with $R^{2}=0.489$, Capacity $(V m)=1705.128$ cur/hour, Density (Dm) V=58.82 skr/km, Maximum speed $(\mathrm{Sm})=28.988 \mathrm{~km} / \mathrm{hour}$. Of the three models, namely Greenshield, Greenberg, and Underwood, which are close to the capacity value using PKJI 2014 with a capacity of $V m=2794.1$ skr/hour is the Underwood model on Friday in segment 2 direction H. Ikap-Iskandar with a capacity of $V m=2800,382$ cur/hour with $r^{2}=0.243$ the relationship between $(S-D) S=68,511 x \exp (-D / 111.11)$ equation $(V-S) V=111.11 S x$ Ln $(68,511 / S)$ equation $(V-D) V=68,511 . D \exp (-D / 111.11)$.

Keyword: greenberg, greenshield, underwood, PKJI 2014.

\section{PENDAHULUAN}

Kota Palangka Raya adalah salah satu kota yang sedang berkembang saat ini dengan seiringnya waktu maka kemajuan perekonomianpun semangkin meningkat. Peningkatan tersebut beriringan dengan meningkatan sarana transportasi yang akan berdampak pada keadaan lalu lintas di setiap jalan terutama pada jalan perkotaan. Jalan Ahmad Yani adalah salah satu jalan perkotaan yang terdapat di kota Palangka Raya yang memiliki volume lalu lintas kendaraan yang cukup tinggi dengan sepanjang jalan terdapat pertokoan, kantor dan beberapa instansi pemerintah seperti sekolah dan rumah sakit yang menyebabkan banyaknya kendaraan berhenti di sepanjang ruas jalan pada waktu tertentu. Sehingga pergerakan lalu lintas yang terjadi di Jalan Ahmad Yani cukup padat yang akan di khawatirkan akan terjadi kemacetan dan permasalah lainnya. Untuk mengetahui bagaimana keadaan lalu lintas yang terjadi di Jalan Ahmad Yani maka perlu dilakukan analisa kapasitas Jalan Ahmad yani dengan metode PKJI 2014 dan membuat perbandingan perhitungan kapasitas jalan menggunakan metode Greenshields, Greenberg dan Underwood

\section{Tujuan Penelitian}

Tujuan dari penelitian ini adalah untuk mengetahui hubungan matematis antara volume, kecepatan dan kepadatan lalu lintas, untuk mengetahui kapasitas dan tingkat layanan ruas Jalan Ahmad Yani Kota Palangka Raya. Dan membandingkan metode perhitungan mana yang mendekati atau sesuai dengan perhitungan kapasitas berdasarkan PKJI untuk jalan perkotaan.

\section{METODE PENELITIAN}

\section{Lokasi Penelitian}

Penelitian ini dilakukan di Jalan Ahmad Yani Kota Palangka Raya, Provinsi Kalimantan Tengah, Indonesia. 


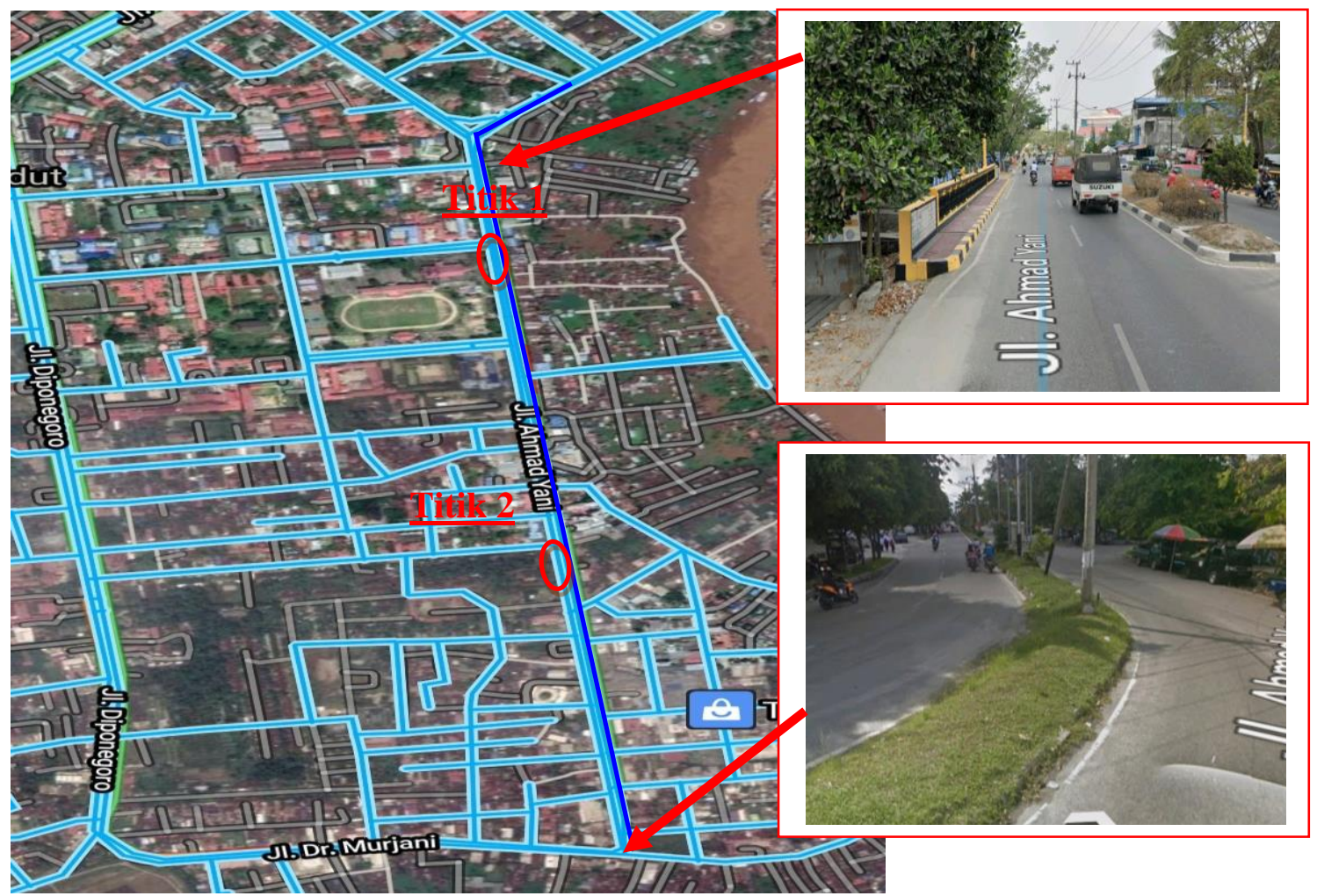

Gambar 1. Lokasi Penelitian

Sumber : Google Maps

\section{Tahap Studi Pustaka}

Studi pustaka merupakan teknik pengumpulan data dan informasi dengan menelaah sumber-sumber tertulis seperti jurnal ilmiah, buku refrensi, literatur, serta sumber lain yang terpercaya dalam bentuk tulisan yang relevan dan berhubungan dengan objek yang sedang diteliti. Berdasarkan dari beberapa refrensi yang dipelajari akan didapat beberapa teori dan rumusan masalah yang telah diuji kebenarannya dan di akui secara umum.

\section{Tahap Persiapan}

Tahapan persipan dilakukan sebelum memulai kegiatan penelitian. Tahapan ini dimulai dari studi literatur serta mempersiapkan alat dan bahan yang akan digunakan dalam kegiatan penelitian. Untuk mengetahui besar arus lalu lintas dan keccepatan yang terjadi pada ruas jalan Ahmad yani alat dan bahan yang digunakan adalah sebagai berikut :

1. Meteran atau pita ukur

2. Cat warna merah

3. Counter

4. Stop wacth

5. Alat tulis dan fromulir survei

\section{Survei Pendahuluan}

Survei pengamatan awal secar visual pada lokasi penelitian. Survei ini bertujuan untuk mengetahui situasi dan kondisi di jalan yang akan dilakukan survei. Survei pendahuluan dimulai dari pengukuran panjang jalan dan pengukuran melintang 
jalan, serta menentukan titik awal dan titik akhir segmen yang akan menjadi titiktitik lokasi pengamatan yang akan dilakukan penelitian.

\section{Tahap Identifikasi Masalah}

Tahapan ini sebagai kelanjutan dari survei pendahuluan yang bertujuan untuk mengetahui kapasitas dan kondisi arus lalu lintas yang terjadi pada ruas jalan Ahmad Yani.

\section{Tahap Pengumpulan Data}

Tahap pengumpulan data bertujuan untuk mendapapatkan seluruh data mentah yang akan digunakan untuk perhitungan kapasitas jalan dan kecepatan arus lalu lintas. Tahap ini terdiri dari identifikasi jenis data yang diperlukan dan metode penelitian

\section{Identifikasi Jenis Data Yang Diperlukan}

Identifikasi jenis data bertujuan untuk mengelompokan data-data yang diperlukan untuk perhitungan analisa kapasitas jalan. Adapun jenis data yang diperlukan adalah sebagai berikut :

1. Data primer yang diperoleh secara langsung berupa hasil pengamatan secara langsung. Adapun data primer yang dibutuhkan dalam analisa adalah sebagai berikut :

a. Kondisi geometri jalan meliputi panjang jalan, lebar jalan, jumlah jalur, lebar bahu jalan, lebar jalur dan lebar median jalan.

b. Kecepatan

c. Volume lalu lintas

2. Data sekunder yang diperlukan dalam analisa kapasitas jalan adalah data jumlah penduduk kota Palangka Raya yang akan didapat dari instansi terkait yaitu BPS kota Palangka Raya.

\section{Perumusan Metode Penelitian}

Bertujuan untuk menentukan metode yang paling tepat dalam pengumpulan data sehingga di dapat data yang dibutuhkan dengan mudah tetapi dapat memenuhin persyaratan dan spesifikasi yang ditentukan. Pada tahap ini dirumuskan tata cara pengambilan data baik di tinjau dari aspek teknis pengumpulan data dan maupun aspek kualitatif. Metode pengambilan data adalah sebagi berikut :

1. Metode literatur : mengumpulkan, mengidentifikasi serta mengolah data dan metode kerja yang dapat dipergunakan sebagai input pembahasan materi.

2. Metode observasi : melakukan peninjauan lapangan secara langsung.

\section{Tahap Pelaksanaan Dan Pengumpulan Data}

Pada tahap ini seluruh data yang diperlukan dalam pengerjaan tugas akhir dikumpulkan baik data sekunder maupun data primer, sehingga maksud dan tujuan penelitian dapat dicapai.

\section{Data sekunder}

Data sekunder yang diperlukan adalah jumlah data penduduk dan peta situasi jalan Ahmad yani kota Palangka Raya yang akan diperoleh melalui instansi terkait yaitu badan perhitungan statistik (BPS) kota Palangka Raya. 


\section{Data primer}

Data primer adalah data yang diperoleh dari hasil survei yang dilakukan. Dari survei yang dilakukan diharapkan akan diperoleh data lapangan dan kondisi nyata dari tempat penelitian. Survei yang dilakukan bertujuan untuk memperoleh data sabagai berikut :

1. Data geometri jalan

2. Kecepatan

3. Volume lalu lintas

\section{Survei Pengambilan Data}

\section{Data geometri jalan}

Geometrik adalah dimensi yang nyata dari suatu jalan beserta bagian-bagian yang disesuaikan dengan tuntutan serta sifat-sifat lalu lintasnya. Informasi tentang kondisi geometrik jalan dalam menganalisa kinerja lalu lintas sangatlah penting. Data geometrik yang didapat akan mempengaruhi penentuan faktor penyesuaian untuk perhitungan dan penentuan kinerja lalu lintas. Adapun data geometrik yang diperlukan dalam penelitian ini adalah:
a. Panjang Jalan (m)
b. Lebar Jalan, lebar bahu jalan dan lebar median jalan (m)
c. Tipe Jalan
d. Jumlah jalur dan Lajur

2. Data kecepatan

Adapun pengambilan data kecepatan di lakukan pada saat yang bersamaan dengan data volume kendaraan. Cara pengambilan data kecepatan yaitu dengan cara mengamati kendaraan yang melewati ruas jalan yang telah ditentukan dengan memperhatikan waktu tempuh yang diperlukan kendaraan untuk melintas menggunakan stop watch. Kemudian pengamat mencatat waktu tempuh kendaraan yang telah diamati itu kedalam formulir survei. Peralatan yang dibutuhkan adalah stop wach atau jam digital, formulir survei dan alat tulis.

3. Data volume lalu lintas

Dengan mencatat jumlah kendaraan yang melalui suatu titik tinjauan yang telah ditetapkan dalam interval 15 menit. Dalam melaksanakan survei ini, kendaraan yang melewati titik pengamatan dibedakan dalam beberapa jenis yaitu:

a. Kendaraan ringan (KR) Terdiri dari kendaraan bermotor beroda 4 termasuk mobil penumpang.

b. Sepeda Motor (SM) Terdiri dari kendaraan bermotor beroda 2 atau 3 termasuk sepeda motor dan kendaraan roda 3 lainnya.

c. Kendaran tidak bermotor Terdiri dari kendaraan yang tak bermotor yang digerakan oleh manusia ataupun hewan, seperti : sepeda, kereta kuda, kereta dorong dll.

Alat yang digunakan yaitu formulir counter, formulir survei, dan alat tulis.

\section{Waktu Pengamatan}

Waktu pengamatan di tentukan berdasarkan volume lalu lintas puncak dari hasil survei pendahuluan yang telah dilakukan maka dapat diketahui waktu pelaksanaan survei sebagai berikut :

1. Pagi hari dimulai dari pukul $06.00-08.00$ WIB.

2. Siang hari dimulai dari pukul $11.00-13.00$ WIB.

3. Sore hari dimulai dari pukul 16.00-18.00 WIB. 
Survei dilakukan selama 5 hari sesuai dengan waktu-waktu yang telah ditentukan dengan interval waktu pencatatan dilakukan setiap 15 menit.

\section{Personil Pengamatan}

Personil yang dibutuhkan untuk pelaksanaan survei kecepatan dan volume lalu lintas di butuhkan sebanyak 2 orang pengamat untuk setiap ruas jalan di satu titik pengamatan.

\section{Tahap Pengolahan Data}

Pada tahap ini data primer yang didapat dari survei lalu lintas yang berupa jumlah kendaraan/jam diolah menjadi data lalu lintas dalam skr/jam dan untuk data kecepatan diperoleh dari pencatatan waktu tempuh kendaraan.

\section{Analisa Regresi Linier}

Regresi linier adalah metode statistik yang dapat digunakan untuk mempelajari hubungan antar sifat permasalahan yang sedang diselidiki. Model analisis regresi linier dapat memodelkan hubungan antara dua perubah atau lebih. Pada model ini terdapat perubah tidak bebas (y) yang mempunyai hubungan fungsional dengan satu atau lebih peubah bebas $\left(\mathrm{x}_{\mathrm{i}}\right)$.

\section{Analisa Korelasi}

Derajat atau tingkat hubungan antara dua variabel diukur dengan Indeks Korelasi, yang disebut sebagai koefisien korelasi dan ditulis dengan simbol R. Apabila nilai koefisien korelasi tersebut dikuadratkan $\left(\mathrm{R}^{2}\right)$, maka disebut sebagai koefisien determinasi yang berfungsi untuk melihat sejauh mana ketepatan fungsi regresi.

\section{Analisa Regresi Non Linier/Kurva Estimasi}

Di samping peramalan dengan analisa regresi linier juga dalam penelitian ini dipakai metode regresi non linier atau disebut juga kurva estimasi. Regresi non linier merupakan suatu cara membuktikan suatu hipotesis jika regresi liniernya tidak didapat yaitu dilihat letak titik-titik liniernya dalam diagram sangat menyimpang dari letak titik-titik yang sebenarnya.

\section{Analisa Data}

\section{HASIL \& PEMBAHASAN}

Ada tiga jenis permodelan yang dapat digunakan untuk mengetahui hubungan matematis antara kecepatan, kepadatan, dan volume yaitu: Model Greenshields, Greenberg, dan Underwood

\section{Perhitungan Arah W.Sudirohosodo-AIS Nasution}

1. Perhitungan Pada Hari Kamis Tanggal 22/10/2020

a. Metode Underwood

Hubungan kecepatan dan kepadatan

$\mathrm{S}=\mathrm{Sff} . \operatorname{Exp}(-\mathrm{D} / \mathrm{Dm})$

asumsi $y=a+b x$

memisahkan $\mathrm{y}=\ln \mathrm{S} ; \mathrm{a}=\ln \mathrm{Sff} ; \mathrm{b}=-1 / \mathrm{Dm}$ dan $\mathrm{x}=\mathrm{D}$.

Data untuk perhitungan regresi linier selanjutnya disajikan pada tabel 1 . 
JURNAL KACAPURI

JURNAL KEILMUAN TEKNIK SIPIL

Volume 4 Nomor 1 Edisi Juni 2021

Tabel 1. Perhitungan Metode Underwood Pada Jalan Ahmad Yani Pada Hari Kamis Tanggal 22/10/2020 (Arah W.Sudirohosodo- AIS Nasution)

\begin{tabular}{|c|c|c|c|c|c|c|c|c|}
\hline \multirow{2}{*}{ NO } & Volnme & kecepatan (km/jam) & kepadatan (skr/lm) & \multirow{2}{*}{$\mathbf{x}$} & \multirow{2}{*}{$\mathbf{Y}=\mathbf{L} \mathbf{n} \mathbf{~}$} & \multirow{2}{*}{$\mathbf{x}^{\wedge} \mathbf{2}$} & \multirow{2}{*}{$\mathbf{y}^{\wedge} \mathbf{2}$} & \multirow{2}{*}{$\mathbf{y}^{*} \mathbf{X}$} \\
\hline & (skr/jam) & $\mathbf{s}$ & $D=v / S$ & & & & & \\
\hline 1 & 575 & 52 & 11,15 & 11,15 & 3,94 & 124,38 & 15,55 & 43,97 \\
\hline 2 & 660 & 68 & 9,75 & 9,75 & 4,21 & 95,01 & 17,76 & 41,08 \\
\hline 3 & 653 & 46 & 14,22 & 14,22 & 3,83 & 202,11 & 14,64 & 54,40 \\
\hline 4 & 765 & 50 & 15,33 & 15,33 & 3,91 & 234,86 & 15,29 & 59,93 \\
\hline 5 & 748 & 60 & 12,43 & 12,43 & 4,10 & 154,55 & 16,79 & 50,94 \\
\hline 6 & 788 & 68 & 11,64 & 11,64 & 4,21 & 135,60 & 17,76 & 49,08 \\
\hline 7 & 744 & 80 & 9,28 & 9,28 & 4,38 & 86,20 & 19,22 & 40,70 \\
\hline 8 & 733 & 55 & 13,32 & 13,32 & 4,01 & 177,42 & 16,07 & 53,39 \\
\hline 9 & 1076 & 53 & 20,26 & 20,26 & 3,97 & 410,66 & 15,78 & 80,49 \\
\hline 10 & 1092 & 60 & 18,14 & 18,14 & 4,10 & 329,04 & 16,79 & 74,33 \\
\hline 11 & 1201 & 39 & 30,42 & 30,42 & 3,68 & 925,39 & 13,51 & 111,81 \\
\hline 12 & 1311 & 41 & 31,90 & 31,90 & 3,72 & 1017,36 & 13,81 & 118,52 \\
\hline 13 & 1267 & 47 & 26,92 & 26,92 & 3,85 & 724,66 & 14,83 & 103,68 \\
\hline 14 & 1197 & 63 & 18,86 & 18,86 & 4,15 & 355,54 & 17,23 & 78,27 \\
\hline 15 & 1230 & 62 & 19,75 & 19,75 & 4,13 & 390,25 & 17,07 & 81,62 \\
\hline 16 & 1257 & 57 & 22,06 & 22,06 & 4,04 & 486,81 & 16,34 & 89,19 \\
\hline 17 & 1177 & 66 & 17,82 & 17,82 & 4,19 & 317,39 & 17,56 & 74,66 \\
\hline 18 & 1197 & 52 & 23,17 & 23,17 & 3,94 & 536,91 & 15,56 & 91,40 \\
\hline 19 & 1199 & 56 & 21,41 & 21,41 & 4,03 & 458,47 & 16,20 & 86,19 \\
\hline 20 & 1328 & 53 & 25,16 & 25,16 & 3,97 & 632,94 & 15,73 & 99,78 \\
\hline 21 & 1337 & 64 & 20,95 & 20,95 & 4,16 & 438,88 & 17,27 & 87,07 \\
\hline 22 & 1259 & 57 & 22,11 & 22,11 & 4,04 & 488,67 & 16,34 & 89,36 \\
\hline 23 & 1115 & 66 & 16,81 & 16,81 & 4,19 & 282,74 & 17,59 & 70,52 \\
\hline 24 & 1216 & 54 & 22,69 & 22,69 & 3,98 & 514,89 & 15,85 & 90,33 \\
\hline$?$ & 25125 & 1369 & 456 & 456 & 97 & 9521 & 391 & 1821 \\
\hline \multicolumn{2}{|c|}{$y=4,367-0,017 x$} & $R^{2}=0,433$ & $a=4,367$ & $b=-0,017$ & \multicolumn{2}{|c|}{ Sf $=\exp (a)=78,80$} & \multicolumn{2}{|c|}{$\mathrm{Dm}=-1 / \mathrm{b}=58,82$} \\
\hline
\end{tabular}

Maka persamaan eksponensial adalah :

$\mathrm{S}=78,80 \times \exp (-\mathrm{D} / 58,82)$

Berdasarkan koefisien determinasi yang diperoleh $r^{2}=0,433$ disimpulkan bahwa hubungan regresi antara variabel baik dan hubungan korelasi kuat dengan $r=0,658$.

Hubungan Volume Dan Kecepatan

$\mathrm{V}=\mathrm{S} . \mathrm{Dm} . \mathrm{Ln}(\mathrm{Sff} / \mathrm{S})$

$\mathrm{V}=\mathrm{S} .58,82 . \operatorname{Ln}(78,80 / \mathrm{S})$

Hubungan Volume Dan Kepadatan

$\mathrm{V}=\mathrm{D}$. Sff . Ln (-D/Dm)

$\mathrm{V}=. \mathrm{D} .78,80 \exp (-\mathrm{D} / 58,82)$

Volume Maksimum (Vmaks)

Vmaks $=(\mathrm{Dj} \times \mathrm{Sff}) / \mathrm{e}$

$$
\begin{aligned}
& =(58,82 \times 78,80) / \mathrm{exp} \quad(\text { catatan }: \text { Nilai e }=2,718282) \\
& =1705,126 \mathrm{skr} / \mathrm{jam}
\end{aligned}
$$

\section{Perhitungan Arah AIS Nasution-W.Sudirohosodo}

1. Perhitungan Pada Hari Selasa Tanggal 20/10/2020

a. Metode Underwood

Hubungan kecepatan dan kepadatan

$\mathrm{S}=$ Sff. $\operatorname{Exp}(-\mathrm{D} / \mathrm{Dm})$

asumsi $y=a+b x$

memisalkan $\mathrm{y}=\ln \mathrm{S} ; \mathrm{a}=\ln \mathrm{Sff} ; \mathrm{b}=-1 / \mathrm{Dm}$ dan $\mathrm{x}=\mathrm{D}$. Data untuk perhitungan

regresi linier selanjutnya disajikan pada tabel 2. 
Tabel 2. Data Regresi Metode Underwood Pada Jalan Ahmad Yani Pada Hari Selasa Tanggal 20/10/2020 (Arah AIS Nasution - W.Sudirohosodo)

\begin{tabular}{|c|c|c|c|c|c|c|c|c|}
\hline \multirow{2}{*}{ NO } & Volume & kecepatan (km/jam) & kepadatan (skr/km) & \multirow{2}{*}{$x$} & \multirow{2}{*}{$\mathrm{Y}=\mathrm{Ln} \mathrm{s}$} & \multirow{2}{*}{$x^{\wedge} 2$} & \multirow{2}{*}{$\mathbf{y}^{\wedge} \mathbf{2}$} & \multirow{2}{*}{$\mathbf{y} * \mathbf{X}$} \\
\hline & (skr/jam) & $\mathrm{s}$ & $\mathrm{D}=\mathrm{V} / \mathrm{S}$ & & & & & \\
\hline 1 & 534 & 63 & 8,52 & 8,52 & 4,14 & 72,60 & 17,13 & 35,26 \\
\hline 2 & 591 & 56 & 10,56 & 10,56 & 4,03 & 111,50 & 16,20 & 42,50 \\
\hline 3 & 619 & 58 & 10,68 & 10,68 & 4,06 & 114,09 & 16,48 & 43,37 \\
\hline 4 & 727 & 44 & 16,62 & 16,62 & 3,78 & 276,38 & 14,28 & 62,81 \\
\hline 5 & 737 & 57 & 12,92 & 12,92 & 4,04 & 166,96 & 16,35 & 52,25 \\
\hline 6 & 796 & 55 & 14,37 & 14,37 & 4,01 & 206,56 & 16,11 & 57,69 \\
\hline 7 & 752 & 64 & 11,76 & 11,76 & 4,16 & 138,31 & 17,29 & 48,90 \\
\hline 8 & 730 & 68 & 10,78 & 10,78 & 4,21 & 116,25 & 17,76 & 45,44 \\
\hline 9 & 1080 & 58 & 18,62 & 18,62 & 4,06 & 346,82 & 16,48 & 75,61 \\
\hline 10 & 1137 & 53 & 21,25 & 21,25 & 3,98 & 451,64 & 15,84 & 84,57 \\
\hline 11 & 1170 & 68 & 17,29 & 17,29 & 4,21 & 298,94 & 17,76 & 72,87 \\
\hline 12 & 1207 & 60 & 20,05 & 20,05 & 4,10 & 402,12 & 16,79 & 82,17 \\
\hline 13 & 1344 & 56 & 24,00 & 24,00 & 4,03 & 575,91 & 16,20 & 96,60 \\
\hline 14 & 1258 & 58 & 21,71 & 21,71 & 4,06 & 471,21 & 16,48 & 88,13 \\
\hline 15 & 1336 & 41 & 32,31 & 32,31 & 3,72 & 1044,20 & 13,85 & 120,26 \\
\hline 16 & 1225 & 39 & 31,69 & 31,69 & 3,66 & 1003,94 & 13,36 & 115,81 \\
\hline 17 & 1150 & 43 & 26,57 & 26,57 & 3,77 & 705,89 & 14,19 & 100,10 \\
\hline 18 & 1078 & 43 & 25,24 & 25,24 & 3,75 & 637,22 & 14,09 & 94,77 \\
\hline 19 & 1211 & 48 & 25,36 & 25,36 & 3,87 & 643,11 & 14,95 & 98,04 \\
\hline 20 & 1298 & 55 & 23,58 & 23,58 & 4,01 & 556,03 & 16,07 & 94,51 \\
\hline 21 & 1343 & 68 & 19,85 & 19,85 & 4,21 & 394,00 & 17,76 & 83,66 \\
\hline 22 & 1178 & 60 & 19,56 & 19,56 & 4,10 & 382,64 & 16,79 & 80,16 \\
\hline 23 & 1114 & 55 & 20,24 & 20,24 & 4,01 & 409,86 & 16,07 & 81,15 \\
\hline 24 & 1098 & 60 & 18,23 & 18,23 & 4,10 & 332,42 & 16,79 & 74,71 \\
\hline$\Sigma$ & 24712 & 1330 & 462 & 462 & 96 & 9859 & 385 & 1831 \\
\hline \multicolumn{2}{|r|}{$+4,337$} & $\mathrm{R}^{2}=0,489$ & $a=4,337$ & $\mathrm{~b}=-0,017$ & \multicolumn{2}{|c|}{$\mathrm{Sf}=\exp (\mathrm{a})=78,80$} & \multicolumn{2}{|c|}{$D m=-1 / b=58,82$} \\
\hline
\end{tabular}

Maka persamaan adalah :

$\mathrm{S}=78,80 \mathrm{x} \exp (\mathrm{D} / 58,82)$

Berdasarkan koefisien determinasi yang diperoleh $r^{2}=0,489$ disimpulkan bahwa hubungan regresi antara variabel kecil dan hubungan korelasi kuat dengan $r=0,699$

Hubungan Volume Dan Kecepatan

$\mathrm{V}=\mathrm{S} . \mathrm{Dm} . \mathrm{Ln}(\mathrm{Sff} / \mathrm{S})$

$\mathrm{V}=58,82 \mathrm{~S} . \operatorname{Ln}(78,80 / \mathrm{S})$

Hubungan Volume Dan Kepadatan

$\mathrm{V}=\mathrm{D}$. Sff . $\exp (-\mathrm{D} / \mathrm{Dm})$

$\mathrm{V}=78,80 \mathrm{D} \cdot \exp (-\mathrm{D} / 58,82)$

Volume Maksimum (Vmaks)

Vmaks $=($ Dj $\times$ Sff $) / e$

$$
\begin{aligned}
& =(78,80 \times 58,82) / \mathrm{exp} \quad(\text { catatan }: \text { Nilai e }=2,718282) \\
& =1705,128 \mathrm{skr} / \mathrm{jam}
\end{aligned}
$$

\section{Perhitungan Arah H.Ikap-Iskandar}

1. Perhitungan Pada Hari Selasa Tanggal 20/10/2020

a. Metode Greenberg

Hubungan Kecepatan dan Kepadatan

$\mathrm{S}=\mathrm{S} \_\mathrm{m} \operatorname{lnDj} / \mathrm{D}$

Untuk mendapatkan nilai konstan $S_{\mathrm{m}}$ dan $\mathrm{Dj}$ maka persamaan diatas diubah menjadi persamaan linier: $\mathrm{Y}=\mathrm{a}+\mathrm{bx}$. Dengan memisalkan $\mathrm{Y}=\mathrm{S}, \mathrm{a}=\mathrm{Sm} . . \mathrm{LnDj}, \mathrm{b}=-\mathrm{Sm}$ dan $\mathrm{X}=\mathrm{Ln}$ D. Data untuk perhitungan regresi linier selanjutnya disajikan pada tabel 3. 
Tabel 3. Perhitungan Untuk Metode Greenberg Pada Jalan Ahmad Yani Pada Hari Selasa Tanggal 20/10/2020 (Arah H. Ikap - Iskandar)

\begin{tabular}{|c|c|c|c|c|c|c|c|}
\hline \multirow{2}{*}{ Na. } & Volnme & kecepatal (km/jam) & kepadatan (skr/km) & \multirow{2}{*}{$\mathbf{X}=\mathbf{L} \mathbf{m} \mathbf{D}$} & \multirow{2}{*}{$\mathbf{y}^{\wedge} \mathbf{2}$} & \multirow{2}{*}{$\mathbf{x}^{\wedge} \mathbf{2}$} & \multirow{2}{*}{$\mathbf{y}^{\star} \mathbf{X}$} \\
\hline & (skT/jam) & $\mathbf{y}$ & $\mathbf{D}=\mathbf{V} / \mathbf{S}$ & & & & \\
\hline 1 & 558 & 63 & 8,84 & 2,18 & 3988,92 & 4,75 & 137,65 \\
\hline 2 & 597 & 57 & 10,51 & 2,35 & 3224,23 & 5,53 & 133,57 \\
\hline 3 & 619 & 43 & 14,30 & 2,66 & 1872,23 & 7,08 & 115,11 \\
\hline 4 & 675 & 38 & 17,69 & 2,87 & 1457,41 & 8,25 & 109,67 \\
\hline 5 & 786 & 43 & 18,41 & 2,91 & 1823,69 & 8,49 & 124,41 \\
\hline 6 & 697 & 46 & 15,30 & 2,73 & 2076,59 & 7,44 & 124,31 \\
\hline 7 & 681 & 55 & 12,30 & 2,51 & 3067,46 & 6,30 & 138,99 \\
\hline 8 & 678 & 48 & 14,00 & 2,64 & 2347,62 & 6,97 & 127,87 \\
\hline 9 & 1056 & 58 & 18,28 & 2,91 & 3339,10 & 8,44 & 167,92 \\
\hline 10 & 1116 & 44 & 25,46 & 3,24 & 1922,73 & 10,48 & 141,94 \\
\hline 11 & 1159 & 38 & 30,33 & 3,41 & 1460,51 & 11,64 & 130,40 \\
\hline 12 & 1180 & 48 & 24,71 & 3,21 & 2279,62 & 10,29 & 153,14 \\
\hline 13 & 1276 & 41 & 30,97 & 3,43 & 1696,61 & 11,79 & 141,40 \\
\hline 14 & 1383 & 57 & 24,36 & 3,19 & 3224,23 & 10,19 & 181,30 \\
\hline 15 & 1271 & 55 & 22,95 & 3,13 & 3067,46 & 9,82 & 173,53 \\
\hline 16 & 1077 & 48 & 22,28 & 3,10 & 2335,03 & 9,63 & 149,99 \\
\hline 17 & 1023 & 54 & 19,04 & 2,95 & 2887,06 & 8,68 & 158,31 \\
\hline 18 & 1142 & 54 & 21,10 & 3,05 & 2930,63 & 9,30 & 165,08 \\
\hline 19 & 1405 & 43 & 32,74 & 3,49 & 1841,12 & 12,17 & 149,69 \\
\hline 20 & 1124 & 43 & 26,37 & 3,27 & 1815,06 & 10,71 & 139,41 \\
\hline 21 & 1352 & 43 & 31,26 & 3,44 & 1872,23 & 11,85 & 148,94 \\
\hline 22 & 1192 & 45 & 26,42 & 3,27 & 2035,16 & 10,72 & 147,71 \\
\hline 23 & 1223 & 48 & 25,31 & 3,23 & 2335,03 & 10,44 & 156,13 \\
\hline 24 & 1254 & 48 & 25,88 & 3,25 & 2347,62 & 10,59 & 157,64 \\
\hline$?$ & 24526 & 1161 & 518,82 & 72,44 & 57247,33 & 221,54 & 3474,11 \\
\hline \multicolumn{3}{|c|}{$y=80.56-10,66 x$} & $R^{2}=0,313$ & $a=$ Sff $=80,56$ & $\mathrm{~b}=\mathrm{Sm}=10,66$ & \multicolumn{2}{|c|}{$\mathrm{Dj}=\exp (\mathrm{a} / \mathrm{Sm})=1914,52$} \\
\hline
\end{tabular}

Maka persamaan logaritmatik adalah :

$\mathrm{S}=10,66 \times \operatorname{Ln}(1914,52 / \mathrm{D})$

Berdasarkan koefisien determinasi yang diperoleh $r^{2}=0,313$ disimpulkan bahwa hubugan regresi antara variabel sangat kecil dan hubungan korelasi cukup kuat dengan $r=0,559$

Hubungan Volume Dan Kecepatan

$\mathrm{V}=\mathrm{S} . \mathrm{Dj} \cdot \exp (-\mathrm{S} / \mathrm{Sm})$

$\mathrm{V}=1914,52 . \mathrm{S} \cdot \exp (-\mathrm{S} / 10,66)$

Hubungan Volume Dan Kepadatan

$\mathrm{V}=\mathrm{Sm} . \mathrm{D} . \mathrm{Ln}(\mathrm{Dj} / \mathrm{D})$

$\mathrm{V}=10,66 . \mathrm{D} . \mathrm{Ln}(1914,52 / \mathrm{D})$

Volume Maksimum (Vmaks)

Vmaks $=(\mathrm{Dj} \times \mathrm{Sm}) / \mathrm{e}$

$=(1914,52 \times 10,66) / \exp \quad($ catatan $:$ Nilai e $=2,718282)$

$=7507,971 \mathrm{skr} / \mathrm{jam}$

Kecepatan pada saat volume maksimum $\mathrm{S}=\mathrm{Sm}=10,66 \mathrm{~km} / \mathrm{jam}$

Perhitungan Arah Iskandar-H.Ikap

1. Perhitungan Pada Hari Jumat Tanggal 23/10/2020

a. Metode Underwood

Hubungan kecepatan dan kepadatan

$\mathrm{S}=\mathrm{S} f f . \operatorname{Exp}(-\mathrm{D} / \mathrm{Dm})$

asumsi $y=a+b x$ 
memisahkan $\mathrm{y}=\ln \mathrm{S} ; \mathrm{a}=\ln \mathrm{Sff} ; \mathrm{b}=-1 / \mathrm{Dm}$ dan $\mathrm{x}=\mathrm{D}$. Data untuk perhitungan regresi linier ini selanjutnya disajikan pada tabel 4 .

Tabel 4. Perhitungan Metode Underwood Pada Jalan Ahmad Yani Pada Hari Jum'at Tanggal 23/10/2020 (Arah Iskandar - H. Ikap)

\begin{tabular}{|c|c|c|c|c|c|c|c|c|}
\hline \multirow{2}{*}{ no } & Volne & lecepatan (km/jam) & kepadatan (\$dr/km) & \multirow{2}{*}{$x$} & \multirow{2}{*}{$\mathbf{Y}=\mathrm{I}$.n $\mathbf{s}$} & \multirow{2}{*}{$\mathbf{x}^{\wedge} \mathbf{2}$} & \multirow{2}{*}{$\mathbf{y}^{\wedge}$} & \multirow{2}{*}{$\mathbf{y}^{\mathbf{2} \mathbf{x}}$} \\
\hline & [ska/jam) & $\mathbf{s}$ & $D=V / S$ & & & & & \\
\hline 1 & 610 & 46 & 13,36 & 13,36 & 3,82 & 178,50 & 14,60 & 51,04 \\
\hline 2 & 593 & 55 & 10,82 & 10,82 & 4,00 & 117,04 & 16,03 & 43,31 \\
\hline 3 & 663 & 40 & 16,43 & 16,43 & 3,70 & 270,03 & 13,67 & 60,76 \\
\hline 4 & 658 & 42 & 15,64 & 15,64 & 3,74 & 244,49 & 13,98 & 58,46 \\
\hline 5 & 736 & 47 & 15,69 & 15,69 & 3,85 & 246,16 & 14,81 & 60,39 \\
\hline 6 & 802 & 63 & 12,64 & 12,64 & 4,15 & 159,71 & 17,23 & 52,46 \\
\hline 7 & 640 & 47 & 13,58 & 13,58 & 3,85 & 184,48 & 14,84 & 52,33 \\
\hline 8 & 711 & 55 & 12,95 & 12,95 & 4,01 & 167,76 & 16,04 & 51,88 \\
\hline 9 & 1129 & 38 & 29,57 & 29,57 & 3,64 & 874,28 & 13,27 & $107,(\mathrm{BD}$ \\
\hline 10 & 1176 & 52 & 22,54 & 22,54 & 3,95 & 508,05 & 15,64 & 89,14 \\
\hline 11 & 1279 & 57 & 22,41 & 22,41 & 4,04 & 502,41 & 16,35 & 90,64 \\
\hline 12 & 1319 & 40 & 32,65 & 32,65 & 3,70 & 1066,04 & 13,68 & $120,7 n$ \\
\hline 13 & 1377 & 38 & 36,56 & 36,56 & 3,63 & 1336,76 & 13,17 & 132,66 \\
\hline 14 & 1425 & 37 & 38,60 & 38,60 & 3,61 & 1489,90 & 13,02 & 139,30 \\
\hline 15 & 1293 & 49 & 26,65 & 26,65 & 3,88 & 710,45 & 15,07 & 103,47 \\
\hline 16 & 1330 & 57 & 23,25 & 23,25 & 4,05 & 540,33 & 16,38 & 94,08 \\
\hline 17 & 1104 & 37 & 29,93 & 29,93 & 3,61 & 895,84 & 13,02 & 107,98 \\
\hline 18 & 1065 & 52 & 20,32 & 20,32 & 3,96 & 412,90 & 15,67 & 80,45 \\
\hline 19 & 1116 & 38 & 29,30 & 29,30 & 3,64 & 858,20 & 13,25 & 106,64 \\
\hline 20 & 1172 & 53 & 21,91 & 21,91 & 3,98 & 480,04 & 15,84 & 87,19 \\
\hline 21 & 1232 & 47 & 26,18 & 26,18 & 3,85 & 685,39 & 14,83 & 100,83 \\
\hline 22 & 1069 & 47 & 22,81 & 22,81 & 3,85 & 520,28 & 14,80 & 87,76 \\
\hline 23 & 1092 & 41 & 26,66 & 26,66 & 3,71 & 710,92 & 13,78 & 98,99 \\
\hline 24 & 1159 & 36 & 31,7 & 31,7 & 3,60 & 1000,36 & 12,94 & 114,27 \\
\hline$?$ & \multirow{2}{*}{\multicolumn{2}{|c|}{\begin{tabular}{|l|l|}
$24 / 30$ & \\
& $R^{2}=0,437$ \\
\end{tabular}}} & 552 & 552 & 92 & 14169 & 352 & 2092 \\
\hline$y=4,143-0,013 x$ & & & $a=4,143$ & $b=-0,013$ & \multicolumn{2}{|c|}{$\mathrm{Sf}=\mathrm{exp}(\mathrm{a})=62,991$} & \multicolumn{2}{|c|}{$\mathrm{D} m=-1 / \mathrm{b}=76,923$} \\
\hline
\end{tabular}

Maka persamaan adalah :

$\mathrm{S}=62,991 \mathrm{x} \exp (-\mathrm{D} / 76,923)$

Berdasarkan koefisien determinasi yang diperoleh $\mathrm{r}^{2}=0,437$ disimpulkan bahwa hubugan regresi antara variabel sangat kecil dan hubungan korelasi kuat dengan $r$ $=0,661$

Hubungan Volume Dan Kecepatan

$\mathrm{V}=\mathrm{S}$. Dm . Ln (Sff/ S )

$V=76,923 \operatorname{Sx} \operatorname{Ln}(62,991 / S)$

Hubungan Volume Dan Kepadatan

$\mathrm{V}=\mathrm{D}$. Sff . $\exp (-\mathrm{D} / \mathrm{Dm})$

$\mathrm{V}=62,991 . \mathrm{D} \exp (-\mathrm{D} / 76,923)$

Volume Maksimum (Vmaks)

Vmaks $=($ Dm $x$ Sff $) / \mathrm{e}$

$$
\begin{aligned}
& =(76,923 \times 62,991) / \mathrm{exp} \quad(\text { catatan }: \text { Nilai e }=2,718282) \\
& =1782,544 / \mathrm{jam}
\end{aligned}
$$

\section{Perhitungan Kapasitas Jalan Ahmad Yani}

Perhitungan kapasitas jalan Ahmad yani berdasarkan hasil data masukan yang didapat adalah sebagai berikut:

$$
\begin{aligned}
& \mathrm{C}=\mathrm{CO} \times \mathrm{FCLJ} \text { FCPA } \times \text { FCHS x FCUK } \\
& \mathrm{C}=1650 \times 0,96 \times 1 \times 0,98 \times 0,90 \\
& \mathrm{C}=2794,1 \text { skr/jam (untuk } 1 \text { jalur jalan) }
\end{aligned}
$$




\section{Perhitungan Yang Mendekati Dengan Perhitungan Kapasitas Berdasarkan PKJI Untuk Jalan Perkotaan}

1. Perhitungan Arah Iskandar-H.Ikap Hari Jumat Tanggal 23/10/2020

a. Metode Underwood

Hubungan kecepatan dan kepadatan

$\mathrm{S}=$ Sff. $\operatorname{Exp}(-\mathrm{D} / \mathrm{Dm})$

asumsi $y=a+b x$

memisahkan $\mathrm{y}=\ln \mathrm{S} ; \mathrm{a}=\ln \mathrm{Sff} ; \mathrm{b}=-1 / \mathrm{Dm}$ dan $\mathrm{x}=\mathrm{D}$. Data untuk perhitungan regresi linier selanjutnya disajikan pada tabel 5.

Tabel 5. Perhitungan Model Underwood Pada Jalan Ahmad Yani Pada Hari Jum'at Tanggal 23/10/2020 (Arah H. Ikap - Iskandar)

\begin{tabular}{|c|c|c|c|c|c|c|c|c|}
\hline \multirow{2}{*}{ No } & Vohne & kecepatan (km/lam) & kepadatan (skr/ km) & \multirow{2}{*}{$\mathbf{x}$} & \multirow{2}{*}{$\mathbf{Y}=\mathbf{L} \mathbf{n g}$} & \multirow{2}{*}{$\mathbf{x}^{\wedge} \mathbf{2}$} & \multirow{2}{*}{$\mathbf{y}^{\wedge}$} & \multirow{2}{*}{$\mathbf{y}^{*} \mathbf{X}$} \\
\hline & (skr/jam) & $\mathbf{5}$ & $\mathrm{D}=\mathrm{V} / \mathrm{S}$ & & & & & \\
\hline 1 & 577 & 63 & 9,13 & 9,13 & 4,15 & 83,41 & 17,19 & 37,86 \\
\hline 2 & 595 & 58 & 10,29 & 10,29 & 4,06 & 105,95 & 16,46 & 41,76 \\
\hline 3 & 641 & 61 & 10,49 & 10,49 & 4,11 & 110,06 & 16,92 & 43,15 \\
\hline 4 & 701 & 58 & 12,10 & 12,10 & 4,06 & 146,31 & 16,48 & 49,11 \\
\hline 5 & 749 & 56 & 13,37 & 13,37 & 4,03 & 178,87 & 16,20 & 53,83 \\
\hline 6 & 760 & 61 & 12,43 & 12,43 & 4,11 & 154,45 & 16,92 & 51,11 \\
\hline 7 & 697 & 53 & 13,18 & 13,18 & 3,97 & 173,74 & 15,74 & 52,30 \\
\hline 8 & 739 & 57 & 13,02 & 13,02 & 4,04 & 169,47 & 16,32 & 52,58 \\
\hline 9 & 1061 & 55 & 19,37 & 19,37 & 4,00 & 375,08 & 16,03 & 77,54 \\
\hline 10 & 1094 & 57 & 19,21 & 19,21 & 4,04 & 369,13 & 16,34 & 77,67 \\
\hline 11 & 1224 & 53 & 23,06 & 23,06 & 3,97 & 531,74 & 15,78 & 91,60 \\
\hline 12 & 1348 & 46 & 29,55 & 29,55 & 3,82 & 873,35 & 14,60 & 112,91 \\
\hline 13 & 1295 & 54 & 24,14 & 24,14 & 3,98 & 582,79 & 15,86 & 96,14 \\
\hline 14 & 1342 & 55 & 24,38 & 24,38 & 4,01 & 594,37 & 16,07 & 97,72 \\
\hline 15 & 1202 & 62 & 19,33 & 19,33 & 4,13 & 373,73 & 17,06 & 79,84 \\
\hline 16 & 1189 & 63 & 18,73 & 18,7 & 4,15 & 350,81 & 17,23 & $7 \pi, 75$ \\
\hline 17 & 1067 & 63 & 17,07 & 17,07 & 4,14 & 291,34 & 17,10 & 70,58 \\
\hline 18 & 1016 & 53 & 19,10 & 19,10 & 3,97 & $364, \pi$ & 15,79 & 75,89 \\
\hline 19 & 1144 & 68 & 16,90 & 16,90 & 4,21 & 285,61 & 17,76 & 71,23 \\
\hline 20 & 1234 & 66 & 18,62 & 18,62 & 4,19 & 346,66 & 17,59 & 78,09 \\
\hline 21 & 1177 & 62 & 19,00 & 19,00 & 4,13 & 360,95 & 17,03 & 78,40 \\
\hline 22 & 1145 & 63 & $18,0 B$ & 18,03 & 4,15 & 325,10 & 17,23 & 74,84 \\
\hline 23 & 1220 & 52 & 23,65 & 23,65 & 3,94 & 559,17 & 15,55 & 93,24 \\
\hline 24 & 1129 & 66 & $17,0 \mathrm{~B}$ & 17,03 & 4,19 & 289,89 & 17,59 & 71,41 \\
\hline$?$ & 24346 & 1405 & 421 & 421 & 98 & 7997 & 397 & 1707 \\
\hline \multicolumn{2}{|c|}{$y=4,227-0,009 x$} & $R^{2}=0,243$ & $a=4,227$ & $b=-0,009$ & \multicolumn{2}{|c|}{$\mathrm{Sf}=\exp (\mathrm{a})=68,511$} & \multicolumn{2}{|c|}{$D m=-1 / b=111,11$} \\
\hline
\end{tabular}

Maka persamaan adalah :

$\mathrm{S}=68,511 \mathrm{x} \exp (-\mathrm{D} / 111,11)$

Berdasarkan koefisien determinasi yang diperoleh $r^{2}=0,243$ disimpulkan bahwa hubugan regresi antara variabel sangat kecil dan hubungan korelasi cukup kuat dengan $r=0,492$

Hubungan Volume Dan Kecepatan

$\mathrm{V}=\mathrm{S} . \mathrm{Dm} . \mathrm{Ln}(\mathrm{Sff} / \mathrm{S})$

$\mathrm{V}=111,11 \mathrm{Sx} \operatorname{Ln}(68,511 / \mathrm{S})$

Hubungan Volume Dan Kepadatan

$\mathrm{V}=\mathrm{D}$. Sff . $\exp (-\mathrm{D} / \mathrm{Dm})$

$\mathrm{V}=68,511 . \mathrm{D} \exp (-\mathrm{D} / 111,11)$

Volume Maksimum (Vmaks)

Vmaks $=($ Dm $\times$ Sff $) / \mathrm{e}$

$$
\begin{aligned}
& =(111,11 \times 68,511) / \mathrm{exp} \quad(\text { catatan }: \text { Nilai e }=2,718282) \\
& =2800,382 / \mathrm{jam}
\end{aligned}
$$




\section{PENUTUP}

\section{Kesimpulan}

Dari analisis pembahasan yang telah dibuat maka dapat dibuat kesimpulan sebagai berikut :

1. Dari hasil perhitungan hubungan atara kecepatan, kepadatan dan volume diperoleh koefisien determinasi $\left(\mathrm{r}^{2}\right)$. Untuk arah arah W.SudirohosoAIS.Nasution diperoleh koefisien determisasi terbesar dengan menggunakan model Underwood pada hari kamis dengan nilai $\mathrm{R}^{2}=0,433$. Untuk arah AIS.Nasution-W.Sudirohosodo di dapat koefisien determinasi terberasar dengan permodelan Underwood pada hari selasa dengan nilai $\mathrm{R}^{2}=0,489$. Untuk arah arah H.Ikap-Iskandar diperoleh koefisien determisasi terbesar dengan menggunakan model greenberg pada hari selasa dengan nilai $\mathrm{R}^{2}=0,313$. Dan untuk arah Iskandar - H.Ikap diperoleh koefisien determinasi terberasar dengan permodelan Underwood pada hari jum'at dengan nilai $\mathrm{R}^{2}=0,437$.

2. Kapasitas jalan ahmad yani berdasrkan perhitungan pkji 2014 adalah $\mathrm{Vm}=2794,1 \mathrm{skr} / \mathrm{jam}$ (untuk jalur jalan).

3. Dari tiga model yaitu greenshield, greenberg,dan underwood yang mendekati dengan nilai kapasitas menggunakan PKJI 2014 dengan kapasitas Vm= 2794,1skr/jam adalah model underwood pada hari jum'at pada segmen 2 arah H.Ikap-Iskandar dengan kapasitas. $\mathrm{Vm}=2800,382 \mathrm{skr} / \mathrm{jam}$ dengan $\mathrm{r}^{2}=0,243$ hubungan antara $(\mathrm{S}-\mathrm{D}) \mathrm{S}=68,511 \mathrm{x} \exp (-\mathrm{D} / 111,11)$ persamaan $(\mathrm{V}-\mathrm{S}) \mathrm{V}=111,11$ Sx Ln $(68,511 / \mathrm{S})$ persamaan $(\mathrm{V}-\mathrm{D}) \mathrm{V}=68,511 . \mathrm{D} \exp (-\mathrm{D} / 111,11)$.

\section{Saran}

1. Dari hasil survei volume lalu lintas yang terjadi di ruas jalan ahmad yani masih belum tinggi sehingga tidak diperlukan menejemen lalu lintas oleh pemerintah.

2. Untuk hasil studi penelitian dari perhitungan perbandingan kapasitas dan hubungan karakteristik arus lalu lintas yang lebih akurat, sebaiknya dilakukan penelitian tambahan pada segmen lain dari ruas jalan ini..

\section{DAFTAR PUSTAKA}

1. Google inc. 2020. Google Maps: Peta Lokasi Jalan Ahmad Yani Kota Palangka Raya, Provinsi Kalimantan Tengah.

2. Anonim, Pedoman Kapasitas Jalan Indonesia, 2014, Kementerian PUPR, Jakarta.

3. Hobbs, 1995, Perencanaan dan Teknik Lalu Lintas, Gajah Mada Universitas Press, Yogyakarta.

4. Morlock, E. K., Pengantar Teknik dan Perencanaan Transportasi (Terjemahan), Erlangga, Jakarta.

5. Oglesby, Clarkson Hicks., Teknik Jalan Raya Jilid I (Terjemahan). Gramedia. Jakarta.

6. Pignataro, Louis J., Traffic Engineering Theory and Practice, Prentice Hall, Inc.

7. USA Wohl and Martin., Traffic System Analysis for Engineers and Planners, McGraw-Hill Book Company, New York. 